Check for updates

Cite this: Phys. Chem. Chem. Phys. 2020, 22, 18606

Received 23rd May 2020, Accepted 27th July 2020

DOI: $10.1039 / \mathrm{d} 0 \mathrm{cp} 02800 \mathrm{~b}$

rsc.li/pccp

\title{
Free electron laser infrared action spectroscopy of nitrous oxide binding to platinum clusters, $\mathrm{Pt}_{n}\left(\mathrm{~N}_{2} \mathrm{O}\right)^{+} \dagger$
}

\author{
Gabriele Meizyte, (D) ${ }^{a}$ Alice E. Green, (D) ${ }^{a}$ Alexander S. Gentleman, (D) a \\ Sascha Schaller, (iD ${ }^{\mathrm{b}}$ Wieland Schöllkopf, (DD ${ }^{\mathrm{b}}$ André Fielicke (D) ${ }^{\mathrm{bc}}$ and \\ Stuart R Mackenzie (iD) *a
}

\begin{abstract}
Infrared multiple-photon dissociation spectroscopy has been applied to study $\mathrm{Pt}_{n}\left(\mathrm{~N}_{2} \mathrm{O}\right)^{+}(n=1-8)$ clusters which represent entrance-channel complexes on the reactive potential energy surface for nitrous oxide decomposition on platinum. Comparison of spectra recorded in the spectral region $950 \mathrm{~cm}^{-1}$ to $2400 \mathrm{~cm}^{-1}$ with those simulated for energetically low-lying structures from density functional theory shows a clear preference for molecular binding via the terminal $\mathrm{N}$ atom, though evidence of $\mathrm{O}$-binding is observed for some cluster sizes. Enhanced reactivity of $\mathrm{Pt}_{n}{ }^{+} n \geq 6$ clusters towards $\mathrm{N}_{2} \mathrm{O}$ is reflected in the calculated reactive potential energy surfaces and, uniquely in the size range studied, $\mathrm{Pt}_{6}\left(\mathrm{~N}_{2} \mathrm{O}\right)^{+}$ proved impossible to form in significant number density even with cryogenic cooling of the cluster source. Infrared-driven $\mathrm{N}_{2} \mathrm{O}$ decomposition, resulting in the formation of cluster oxides, $\mathrm{Pt}_{n} \mathrm{O}^{+}$, is observed following vibrational excitation of several $\mathrm{Pt}_{n}\left(\mathrm{~N}_{2} \mathrm{O}\right)^{+}$complexes.
\end{abstract}

\section{Introduction}

Nitrous oxide $\left(\mathrm{N}_{2} \mathrm{O}\right)$ is a significant atmospheric pollutant both as a greenhouse gas (GHG) and for the role it plays in ozone depletion. ${ }^{1}$ As a result of its relatively high global warming potential (GWP) coefficient $\mathrm{N}_{2} \mathrm{O}$ is considered to be the third principal long-lived GHG after $\mathrm{CO}_{2}$ and $\mathrm{CH}_{4}{ }^{2}$ and one of the most potent waste gases resulting from human activity that has a significant impact on both the future ozone layer and climate. ${ }^{3} \mathrm{~N}_{2} \mathrm{O}$ discharge is not covered by the Montreal Protocol ${ }^{4}$ but, given its harmful environmental impact, there is considerable interest in using heterogeneous catalysis to reduce anthropogenic emissions. ${ }^{5}$

The platinum group metals (Ru, Rh, Pd, Os, Ir \& Pt) are wellknown heterogeneous catalysts. Platinum metal itself shows versatile catalytic abilities and is frequently used in industrial as well as everyday applications. For example, the production of nitric acid for fertilizers involves ammonia oxidation using a

\footnotetext{
${ }^{a}$ Department of Chemistry, University of Oxford, Physical and Theoretical Chemistry Laboratory, South Parks Road, Oxford, OX1 3QZ, UK. E-mail: stuart.mackenzie@chem.ox.ac.uk

${ }^{b}$ Fritz-Haber-Institut der Max-Planck-Gesellschaft, Faradayweg 4-6, 14195 Berlin, Germany. E-mail: fielicke@fhi-berlin.mpg.de

${ }^{c}$ Institut für Optik und Atomare Physik, Technische Universität Berlin, Hardenbergstraße 36, 10623 Berlin, Germany

$\dagger$ Electronic supplementary information (ESI) available: Containing calculated structures of important species observed experimentally, plus calculated $\mathrm{N}_{2} \mathrm{O}$ binding energies and bond lengths. See DOI: 10.1039/d0cp02800b
}

platinum catalyst. ${ }^{6}$ However, platinum is probably best known for its role, along with palladium and rhodium, in promoting exhaust gas reactions in the automobile catalytic converter (design first developed by R. C. Stempel et al. ${ }^{7}$ ). Highly inert (noble even) in its bulk form, most catalytic applications of platinum make use of it in highly divided, often nanoscale form. In addition to maximizing surface area, this introduces defects into the metal which are not present in extended single crystal surfaces and it is these defect sites which often provide the sites for interesting chemistry. ${ }^{8,9}$

Transition metal clusters serve as tractable model systems for the study of heterogeneous nanocatalysts at the molecular level. ${ }^{10}$ In the gas phase, the fundamental interactions involved in reactive chemistry can be studied in the absence of complex interactions present in real catalysts, such as the influence of substrates, solvation, and aggregation effects, which are challenging to analyse and often obscure the fundamental interactions of interest. ${ }^{11}$ The subject of this study, isolated $\mathrm{Pt}_{n}\left(\mathrm{~N}_{2} \mathrm{O}\right)^{+}$clusters, represent model entrance-channel complexes for the initial chemisorption step in the metal-catalysed decomposition of $\mathrm{N}_{2} \mathrm{O}$.

Reflecting the catalytic properties of platinum, the reactions of platinum clusters, $\mathrm{Pt}_{n}{ }^{+/ 0 /-}$, have received considerable attention previously. A variety of experimental techniques, including flow reactor, molecular beam-gas cell studies, and Fouriertransform ion-cyclotron resonance (FT-ICR) mass spectrometry, have been employed to study the reactions of $\mathrm{Pt}_{n}{ }^{+/ 0 /-}$ with small 
molecules. These include dehydrogenation of small hydrocarbons, ${ }^{12-18}$ as well as $\mathrm{H}_{2}, \mathrm{CO}_{2}, \mathrm{~N}_{2} \mathrm{O}$ etc. ${ }^{19-23} \mathrm{Pt}_{4}{ }^{+}$exhibits particularly low reactivity, also supported by a theoretical investigation, ${ }^{24}$ and a photofragmentation study of bare $\mathrm{Pt}_{n}{ }^{+}$ clusters by Janssens ${ }^{25}$ suggests the reason lies in the anomalously large HOMO-LUMO gap for tetrahedral $\mathrm{Pt}_{4}{ }^{+}$. Interestingly, $\mathrm{Pt}_{4}{ }^{-}$ activates carbon dioxide ${ }^{26}$ and dehydrogenates methane very efficiently, perhaps because of its own planar structure. ${ }^{18,26}$

Of particular relevance here are the single collision studies of $\mathrm{Pt}_{n}^{+/-}$reactions with $\mathrm{N}_{2} \mathrm{O}$ in which the cationic clusters exhibit dramatic size-dependent rate constants changing by several orders of magnitude upon the addition of a single metal atom. ${ }^{22}$ In this small cluster regime, every atom counts. In all cases the reaction proceeds exclusively via an $\mathrm{O}$ atom transfer generating sequential cluster oxides, $\mathrm{Pt}_{n} \mathrm{O}_{m}{ }^{+}$. Additional collisions are required to stabilize the molecular adsorption of $\mathrm{N}_{2} \mathrm{O}$.

Several studies have established catalytic abilities and even full cycles using platinum clusters. Water formation was observed in the catalytic oxidation of $\mathrm{H}_{2}$ on $\mathrm{Pt}_{n}$ for $n=7-30$ by Andersson and Rosén ${ }^{19}$ and Shi and $\operatorname{Ervin}^{27}$ found small $\mathrm{Pt}_{n}{ }^{-}$ ( $n=3-6)$ cluster anions to be effective catalysts for CO oxidation under thermal conditions. A full catalytic cycle of $\mathrm{CO}$ oxidation/ $\mathrm{N}_{2} \mathrm{O}$ reduction for $\mathrm{Pt}_{n}{ }^{+}(n=6-8)$ was reported by Beyer, Bondybey, and coworkers. ${ }^{28}$

$\mathrm{N}_{2} \mathrm{O}$ represents an interesting adsorbate for infrared studies, with the possibility of both $\mathrm{N}$ - or O-binding reflected in the degree of activation. This is very clearly observed in infrared action spectroscopy of $\mathrm{N}_{2} \mathrm{O}$ binding at single metal centers, for example, $\mathrm{M}^{+}\left(\mathrm{N}_{2} \mathrm{O}\right)_{n}\left(\mathrm{M}=\mathrm{Cu}, \mathrm{Ag}, \mathrm{Au},{ }^{29} \mathrm{Co}, \mathrm{Rh}, \mathrm{Ir},{ }^{30}\right.$ and $\left.\mathrm{Li}, \mathrm{Al}^{31}\right)$ by Cunningham et al. These studies have revealed interesting binding motifs and structural isomers as well as the important role played by low-lying electronically excited states.

We have previously studied $\mathrm{N}_{2} \mathrm{O}$ adsorption on small gas-phase $\mathrm{Rh}_{n}{ }^{+}$clusters $\left(\mathrm{Rh}_{n}\left(\mathrm{~N}_{2} \mathrm{O}\right)^{+}, n=4-8\right)^{32,33}$ using the same methods to those employed in this work. Interesting IR-induced reactivity was observed in which excitation of infrared active modes results in $\mathrm{N}_{2} \mathrm{O}$ decomposition and cluster oxide formation. $\mathrm{Rh}_{5}{ }^{+}$proved special in this regard with a single co-adsorbed oxygen atom changing the chemistry observed from $\mathrm{N}_{2} \mathrm{O}$ loss on $\mathrm{Rh}_{5}\left(\mathrm{~N}_{2} \mathrm{O}\right)^{+}$to $\mathrm{Rh}_{5} \mathrm{O}_{2}{ }^{+}$formation from $\mathrm{Rh}_{5}\left(\mathrm{ON}_{2} \mathrm{O}\right)^{+}{ }^{34}$ These results, along with those from related blackbody infrared ${ }^{35}$ and collisional excitation studies ${ }^{36}$ were explained in terms of relative reaction barriers and dissociation thresholds demonstrating how spectral characterization of entrance-channel complexes yields important information on the full reactive potential energy surface.

Here we report the first experimental investigation of cationic platinum clusters with adsorbed nitrous oxide, $\mathrm{Pt}_{n}\left(\mathrm{~N}_{2} \mathrm{O}\right)^{+}(n=1-8)$, using infrared multiple-photon dissociation spectroscopy. Cluster structures, along with relative cluster reactivities, are revealed with the help of complementary quantum chemical calculations.

\section{Experimental methods}

The infrared multiple-photon dissociation (IR-MPD) spectra presented in this report were recorded at the Fritz Haber Institute
(FHI) in Berlin making use of the FHI free electron laser (FEL) ${ }^{37}$ facility. The experimental setup has been described in detail previously $^{38,39}$ and only essential details are described here. Briefly, a rotating natural Pt target is ablated by a Nd:YAG laser $(532 \mathrm{~nm}, 10 \mathrm{~Hz})$. Ablated atoms cool and cluster by colliding with helium within a reaction channel, to which nitrous oxide is added by an additional late-mixing pulsed valve, downstream of the ablation point. The resulting gas mix, now entrained with a range of pure and decorated clusters, expands into the vacuum forming a molecular beam which is then skimmed before entering the extraction region of a reflectron time-offlight (ToF) mass spectrometer used to detect the presence of cationic species. In an attempt to suppress direct oxidation and maximize the generation of molecularly bound $\mathrm{Pt}_{n}\left(\mathrm{~N}_{2} \mathrm{O}\right)^{+}$ clusters, the cluster source was cooled with liquid nitrogen.

To record infrared multiple-photon dissociation (IR-MPD) spectra, the cluster beam is subjected to alternate pulses of output of the FHI FEL, operating for these purposes in the $950-2400 \mathrm{~cm}^{-1}$ range and corresponding parent ion depletion and fragment(s) channel enhancement are recorded as a function of wavenumber. In this way the spectra yield information on the infrared active modes of the parent cluster as well as dissociation branching ratios, which can be compared with the results of DFT simulations.

\section{Computational methods}

Energetically low-lying structures and relevant transition states connecting them have been calculated at the def2TZVP ${ }^{40} /$ TPSSh $^{41,42}$ level, using the Gaussian 16 software package. ${ }^{43}$ This functional reproduces the transition metal-ligand bond dissociation energies ${ }^{44}$ and showed similar energetic ordering of the $\mathrm{Pt}_{n} \mathrm{O}_{2} \mathrm{CO}^{+}$cluster geometries ${ }^{45}$ to using the TPSS $^{42}$ functional that has previously proved to generate reliable IRMPD experimental results. ${ }^{4,47}$ The GD3-BJ dispersion term ${ }^{48}$ was introduced to account for weak intramolecular interactions and a quasirelativistic Wood-Boring effective core potential $(\mathrm{WB}-\mathrm{ECP})^{49}$ was used to freeze 60 inner electrons and introduce relativistic corrections for Pt atoms. As starting structures, the coordinates of bare $\mathrm{Pt}_{n}{ }^{+}$clusters for $n=3-5$ were taken from earlier work by Harding et al. ${ }^{47}$ To provide a better match with experimental data, computed harmonic vibrational frequencies were scaled by a factor of 0.955 , determined by calculating the vibrational frequency of the asymmetric free $\mathrm{N}_{2} \mathrm{O}$ band. ${ }^{50}$ All energies reported here include zero point energies. Potential energy profiles were generated by identifying plausible transition states between two minima and performing Intrinsic Reaction Coordinate (IRC) ${ }^{51,52}$ calculations in order to verify the correct path.

\section{Results and discussion}

\section{A. Time-of-flight spectra and analysis}

Fig. 1(a) shows part of the time-of-flight spectrum for the species produced following ablation of a natural platinum target in the presence of helium with low pressure nitrous oxide introduced downstream via the late mixing valve. We have repeated the 
experiment at a range of $\mathrm{N}_{2} \mathrm{O}$ pressures and these results are representative. A range of $\mathrm{Pt}_{n} \mathrm{O}_{x}{ }^{+}$and $\mathrm{Pt}_{n}\left(\mathrm{~N}_{2} \mathrm{O}\right)_{m}{ }^{+}$clusters are observed. We have previously reported an IR-MPD study of platinum oxide clusters. ${ }^{53}$ Analysis of the time-of-flight spectrum is complicated by the fact that platinum has six stable isotopes, leading to a wide range of masses for the same chemical species. Nevertheless, deconvolution is possible and is illustrated in Fig. 1(b) for the $\mathrm{Pt}_{3}{ }^{+} \mathrm{X}$ species produced. $\mathrm{Pt}_{n} \mathrm{O}_{x}{ }^{+}$ $(x=1,2,3)$ and $\mathrm{Pt}_{n}\left(\mathrm{~N}_{2} \mathrm{O}\right)_{m}{ }^{+}(m=1,2,3)$ dominate the mass spectrum but a trace of $\mathrm{Pt}_{3} \mathrm{C}^{+}$and $\mathrm{Pt}_{3} \mathrm{CO}^{+}$is also observed - the carbon assumed to originate from polishing the target rod.

Quantitative analysis of the mass spectrum, including deconvolution for the isotopes of platinum, leads to the normalized product abundances shown in Fig. 2(a) which yield important information on the relative reactivity of different $\mathrm{Pt}_{n}{ }^{+}$cluster sizes towards $\mathrm{N}_{2} \mathrm{O}$. Reactivity pathways can be visualized as:

(encounter complex formation) $\mathrm{Pt}_{n}{ }^{+}+\mathrm{N}_{2} \mathrm{O} \rightarrow\left[\mathrm{Pt}_{n} \mathrm{~N}_{2} \mathrm{O}^{+}\right]^{*}$
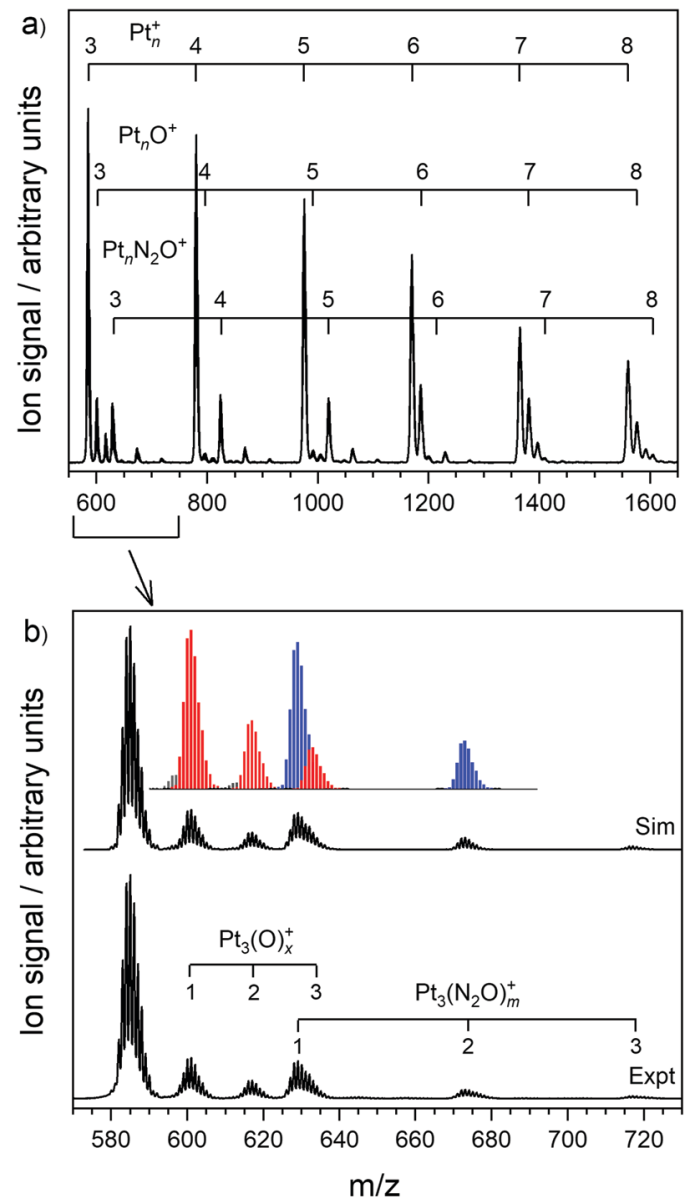

Fig. 1 (a) Time-of-flight mass spectrum; (b) (lower) experimental and (upper) simulated time-of-flight mass spectrum of $\mathrm{Pt}_{3}{ }^{+}$clusters - both produced by laser ablation of a natural platinum rod in helium to which nitrous oxide is added downstream. The cluster source was cooled to $-140{ }^{\circ} \mathrm{C}$ with liquid $\mathrm{N}_{2}$. The principal species produced are simple cluster oxides, $\mathrm{Pt}_{3} \mathrm{O}_{x}{ }^{+}$, and $\mathrm{Pt}_{3}\left(\mathrm{~N}_{2} \mathrm{O}\right)_{m}{ }^{+}$with traces of $\mathrm{Pt}_{3} \mathrm{C}^{+}$and $\mathrm{Pt}_{3} \mathrm{CO}^{+}$.
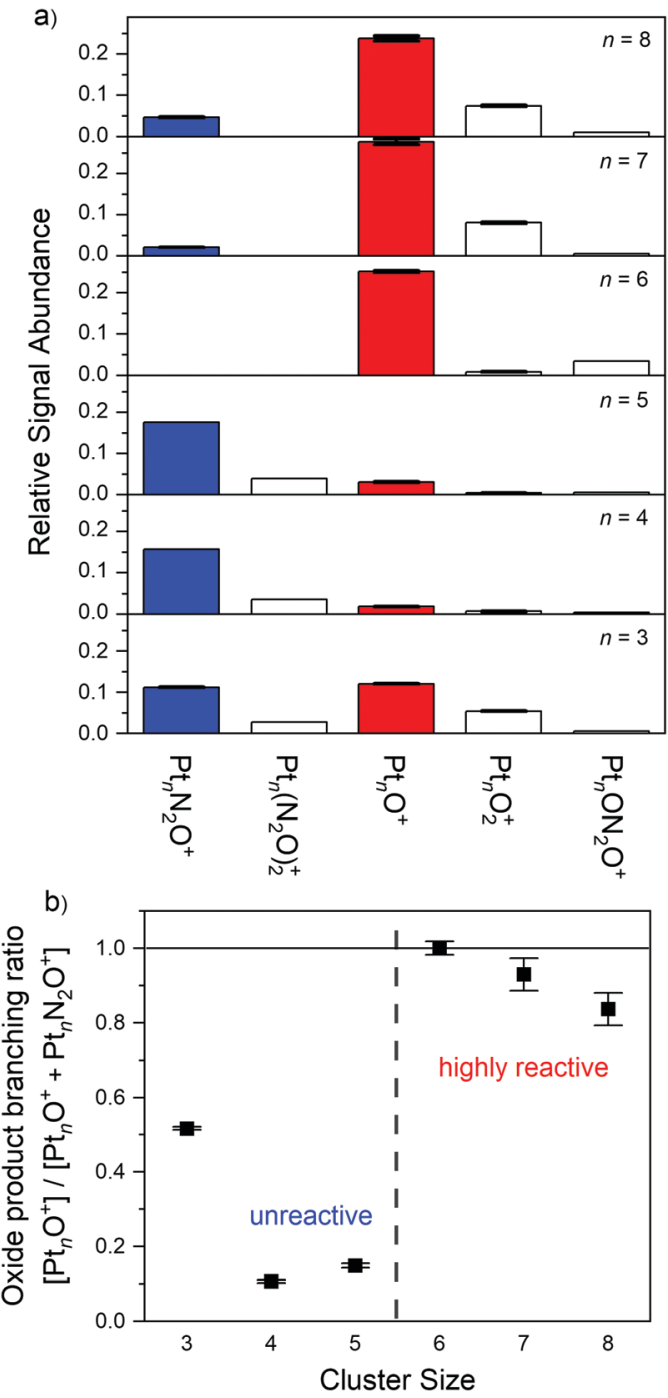

Fig. 2 (a) Histogram with normalised ion abundances (to a unity within each $n ; \mathrm{Pt}_{n}{ }^{+}$not shown) for reaction products generated in the cluster source by the reaction of $\mathrm{Pt}_{n}{ }^{+}(n=3-8)$ with $\mathrm{N}_{2} \mathrm{O}$. The uncertainties shown reflect the fitting of overlapping isotope patterns for different species (see inset Fig. 1(b)); (b) fractional oxide production as a measure of $\mathrm{Pt}_{n}{ }^{+}+\mathrm{N}_{2} \mathrm{O}$ reactivity. A step change in reactivity occurs between $n=5$ and 6 .

In the absence of additional collisions or radiative cooling, this complex must either dissociate or react, in all probability forming the simple cluster oxide for which evidence is observed in the mass spectrum:

(direct dissociation) $\left[\mathrm{Pt}_{n} \mathrm{~N}_{2} \mathrm{O}^{+}\right]^{*} \rightarrow \mathrm{Pt}_{n}{ }^{+}+\mathrm{N}_{2} \mathrm{O}$

(oxidation)

$$
\left[\mathrm{Pt}_{n} \mathrm{~N}_{2} \mathrm{O}^{+}\right]^{*} \rightarrow \mathrm{Pt}_{n} \mathrm{O}^{+}+\mathrm{N}_{2}
$$

The multiple-collision conditions of the cluster source reaction channel permit stabilisation of the initial complex, trapping it in an entrance-channel minimum of the reactive potential energy surface:

$$
\left(\mathrm{N}_{2} \mathrm{O} \text { adsorption) } \quad\left[\mathrm{Pt}_{n} \mathrm{~N}_{2} \mathrm{O}^{+}\right]^{*}+\mathrm{M} \rightarrow \mathrm{Pt}_{n}\left(\mathrm{~N}_{2} \mathrm{O}\right)^{+}+\mathrm{M}\right.
$$

By measuring the charged products we are blind to process (2) but the relative branching ratios for the oxidation reaction 
(3) and molecular adsorption (4) can be quantified as a function of cluster size.

For the $n=3$ cluster under these approximately thermal, multiple collision conditions, the branching ratios for processes (3) and (4) are similar. For $n=4,5$ clusters, however, minimal cluster oxide formation is observed, with $\mathrm{Pt}_{n} \mathrm{~N}_{2} \mathrm{O}^{+}$ being the dominant product. For $n \geq 6$ the situation changes markedly and oxide production dominates. Indeed, for $n=6$ itself, negligible $\mathrm{Pt}_{6} \mathrm{~N}_{2} \mathrm{O}^{+}$is observed. This change in reactivity is highlighted in Fig. 2(b) which shows the $\mathrm{Pt}_{n} \mathrm{O}^{+}$signal as a fraction of total primary products $\left[\mathrm{Pt}_{n} \mathrm{O}^{+}\right] /\left\{\left[\mathrm{Pt}_{n} \mathrm{O}^{+}\right]+\left[\mathrm{Pt}_{n} \mathrm{~N}_{2} \mathrm{O}^{+}\right]\right\}$ as a function of cluster size. The reactions reported here occur under very different conditions to the single collision experiments performed by Balteanu et al. ${ }^{22}$ in which only the direct oxidation process (3) was observed due to the lack of stabilizing collisions required for process (4). Nevertheless, the same step increase in reactivity between $n=5$ and 6 is observed.

In an attempt to better understand the reactivity data, IRC profiles for cluster sizes $n=4-6$ were calculated, as shown in Fig. 3. In each case, the two minima towards the left hand side represent $\mathrm{O}$ - and $\mathrm{N}$-bound entrance-channel complexes of the respective $\mathrm{Pt}_{n}\left(\mathrm{~N}_{2} \mathrm{O}\right)^{+}$species and TS1 - a transition state for $\mathrm{N}_{2} \mathrm{O}$ rotation connecting the two. These entrance channels are separated from the product channel by a potential barrier TS2, which involves significant $\mathrm{N}_{2} \mathrm{O}$ rearrangement, ultimately leading to the production of $\mathrm{Pt}_{n} \mathrm{O}^{+}$cluster and molecular nitrogen. In all cases the overall reaction is calculated to be exothermic by more than $1 \mathrm{eV}$.

The difference in reactivity between $\mathrm{Pt}_{4}{ }^{+}$and $\mathrm{Pt}_{6}{ }^{+}$(reported by Balteanu et $a .^{22}$ as more than three orders of magnitude) is readily attributed to the fact that whilst the former has a real barrier on the ground state surface, in the latter the barrier is submerged. Calculations also show no reactive barrier for either of the two energetically low-lying electronic states of the $n=5$ cluster and thus it is harder to explain the apparent lack of reactivity of this cluster. We note, however, that Balteanu et al. found $\mathrm{Pt}_{5}{ }^{+}$to have intermediate reactivity (a factor ca. 44 less than for $n=6$ ). Caution should be applied when interpreting barrier heights from DFT calculations and we have not performed an exhaustive study with different functionals. The answer may lie in the apparent need for greater fluxionality of the $\mathrm{Pt}_{5}{ }^{+}$cluster during the reaction pathway than the prism/ tetrahedral structures of $\mathrm{Pt}_{6}{ }^{+}$and $\mathrm{Pt}_{4}{ }^{+}$, respectively.

\section{B. IR-MPD spectra}

Fig. 4 shows the IR-MPD spectra recorded in depletion for $\mathrm{Pt}_{n}\left(\mathrm{~N}_{2} \mathrm{O}\right)^{+}(n=1-8)$ in the region $950-2400 \mathrm{~cm}^{-1}$ covering the nitrous oxide $\mathrm{N}=\mathrm{N}$ and $\mathrm{N}=\mathrm{O}$ stretches. In Fig. 4 these bands in the free $\mathrm{N}_{2} \mathrm{O}$ molecules are indicated with dashed lines at around $2224 \mathrm{~cm}^{-1}(\mathrm{~N}=\mathrm{N}$ stretch $)$ and $1285 \mathrm{~cm}^{-1}(\mathrm{~N}=\mathrm{O}$ stretch $)$, respectively. As discussed above, negligible $\mathrm{Pt}_{6}\left(\mathrm{~N}_{2} \mathrm{O}\right)^{+}$is produced and hence no spectrum could be recorded of this species.

The spectra of each species $n \geq 3$ exhibit clear features slightly blue-shifted from the free $\mathrm{N}_{2} \mathrm{O}$ band positions. The presence of these bands, close to those of free nitrous oxide, clearly indicates molecularly-bound $\mathrm{N}_{2} \mathrm{O}$ on the metal cluster.

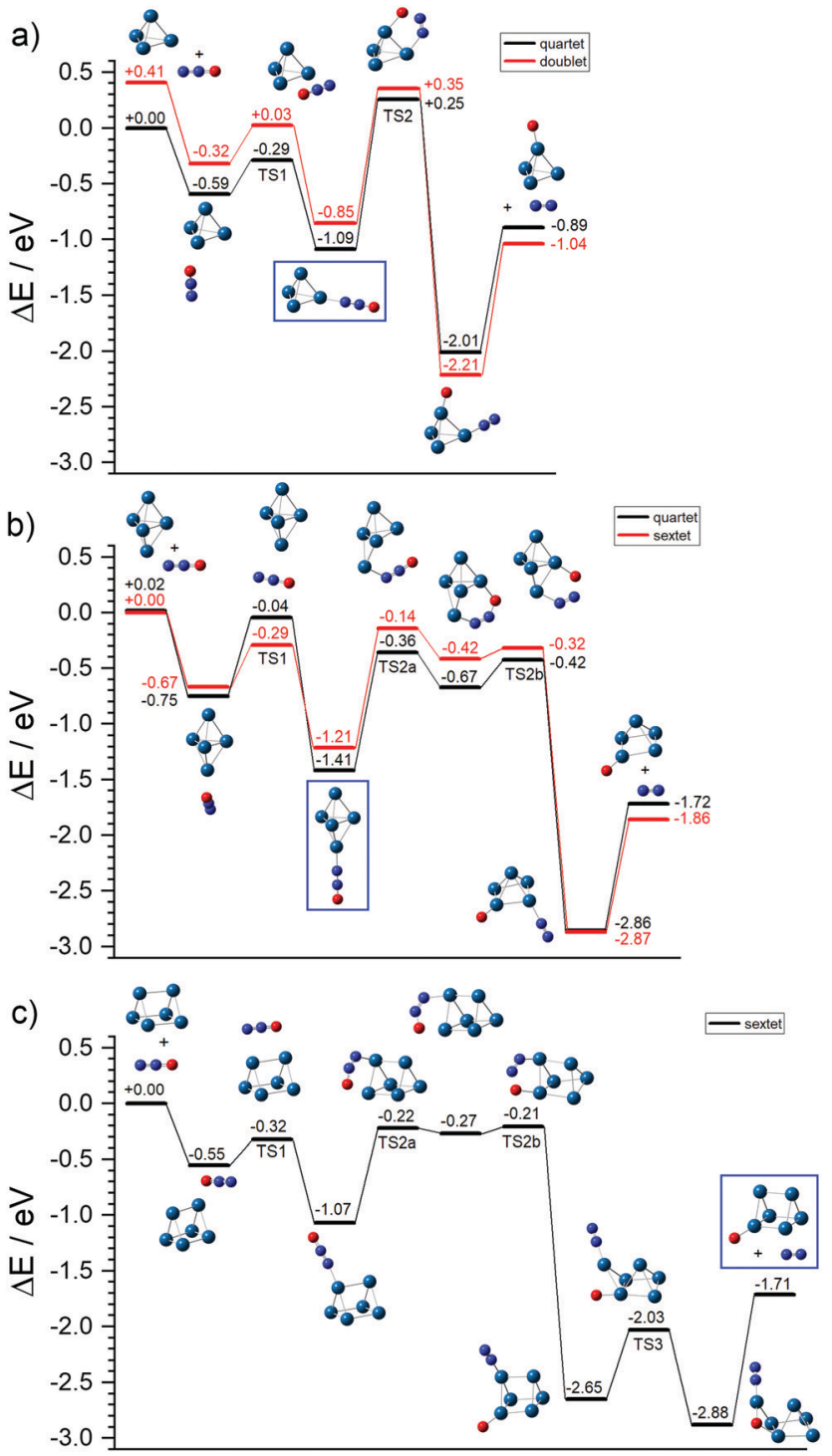

Fig. 3 Intrinsic reaction coordinate for (a) $\mathrm{Pt}_{4}{ }^{+}$, (b) $\mathrm{Pt}_{5}{ }^{+}$, and (c) $\mathrm{Pt}_{6}{ }^{+}+\mathrm{N}_{2} \mathrm{O}$ entrance channels. Blue boxes highlight the predominant species observed in the mass spectrum for each $n$. The barrier to $\mathrm{N}_{2} \mathrm{O}$ dissociation on $\mathrm{Pt}_{n}{ }^{+}$cluster is pronounced for $n=4$ and submerged for $n=6$. This is reflected in the observed reactivity (see Fig. 2); $\mathrm{Pt}_{4}{ }^{+}$is the least reactive favouring $\mathrm{N}_{2} \mathrm{O}$ adsorption whereas $\mathrm{Pt}_{6}{ }^{+}$does not form any adsorption products and mainly produces oxides. Only the lowest electronic states are shown. For $n=4$, geometries of both doublet and quartet are virtually indistinguishable; for $n=5$, they are not - higher in energy sextet structures are given in the ESI. $\dagger$

The blue-shift of both bands indicates preferential N-binding on $n \geq 3$ clusters (supported by computational results below) and reflects the dominance of $\sigma$-donation from the nitrous oxide to the cationic $\mathrm{Pt}_{n}{ }^{+}$cluster over $\pi$-back bonding. For the smallest species, $n=1-2$, the observed vibrational bands are considerably broader and there is evidence of components both blue- and red-shifted with respect to the free $\mathrm{N}_{2} \mathrm{O}$ stretches. Red-shifted bands, especially around the $\mathrm{N}=\mathrm{O}$ stretch, are strong evidence for the presence of O-bound clusters, which have been seen before in similar, higher-resolution infrared 


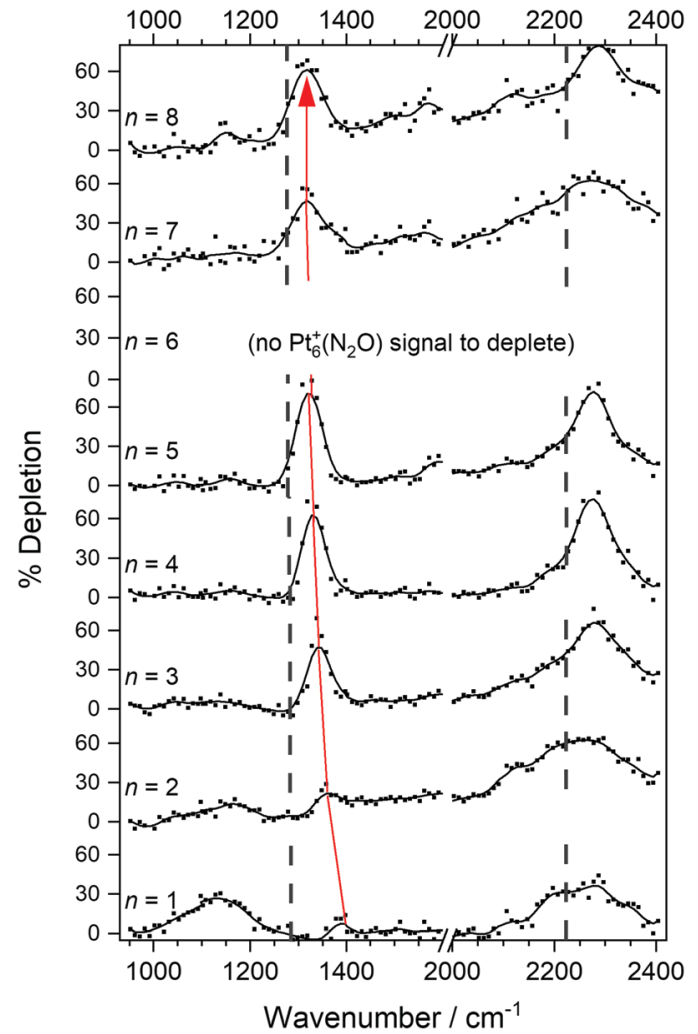

Fig. 4 IR-MPD spectra of $\mathrm{Pt}_{n}\left(\mathrm{~N}_{2} \mathrm{O}\right)^{+}(n=1-8)$ clusters recorded in depletion of the parent cluster ion. The dashed lines at $1285 \mathrm{~cm}^{-1}$ and $2224 \mathrm{~cm}^{-1}$ indicate the wavenumbers of the $\mathrm{N}=\mathrm{O}$ and $\mathrm{N}=\mathrm{N}$ stretches of free $\mathrm{N}_{2} \mathrm{O}$, respectively. ${ }^{50}$

studies of $\mathrm{M}^{+}\left(\mathrm{N}_{2} \mathrm{O}\right)_{n}(\mathrm{M}=\mathrm{Co}, \mathrm{Rh}, \mathrm{Ir}, \mathrm{Cu}, \mathrm{Ag}, \mathrm{Au}, \mathrm{Li}$ and $\mathrm{Al}) .{ }^{29-31}$ The smallest clusters, with fewer degrees of freedom, are less efficiently annealed into lower energy (N-bound) structures, allowing the trapping of energetically higher-lying isomers, including O-bound structures.

The $\mathrm{Pt}_{8}\left(\mathrm{~N}_{2} \mathrm{O}\right)^{+}$cluster is intriguing amongst the larger clusters studied in that its spectrum exhibits both blue- and red-shifted bands in both spectral regions, possibly reflecting a mix of $\mathrm{N}$ - and $\mathrm{O}$-bound structures. The O-bound structure has an $\mathrm{N}=\mathrm{O}$ stretch band, which is red-shifted by $>100 \mathrm{~cm}^{-1}$, compared with the corresponding free $\mathrm{N}_{2} \mathrm{O}$ band, indicating marked molecular activation.

A clear trend is observed in the frequency of the N-bound $\mathrm{N}=\mathrm{O}$ stretching band with cluster size. This band moves smoothly from $1390 \pm 5 \mathrm{~cm}^{-1}$ on $n=1$ to $1315 \pm 5 \mathrm{~cm}^{-1}$ by $n=8$ (shown in Fig. 4 with a red arrow). The same trend is observed in the calculated band positions which move from $1421 \mathrm{~cm}^{-1}$ for $\operatorname{Pt}\left(\mathrm{N}_{2} \mathrm{O}\right)^{+}$to $1287 \mathrm{~cm}^{-1}$ for $\mathrm{Pt}_{5}\left(\mathrm{~N}_{2} \mathrm{O}\right)^{+}$. The broader nature of the band in the $\mathrm{N}=\mathrm{N}$ stretch region makes it harder to discern any such trend in this region.

Fig. 5 compares the experimental spectra of $\mathrm{Pt}_{3}\left(\mathrm{~N}_{2} \mathrm{O}\right)^{+}$and $\mathrm{Pt}_{4}\left(\mathrm{~N}_{2} \mathrm{O}\right)^{+}$with those predicted for energetically low-lying calculated structures. The lowest energy calculated structures are inserted (i.e., dissociative $\mathrm{N}_{2} \mathrm{O}$ adsorption), but given the low binding energy of $\mathrm{N}_{2}$ and the overall exothermicity of the dissociation, it is unlikely that such $\mathrm{Pt}_{n} \mathrm{O}\left(\mathrm{N}_{2}\right)^{+}$structures would

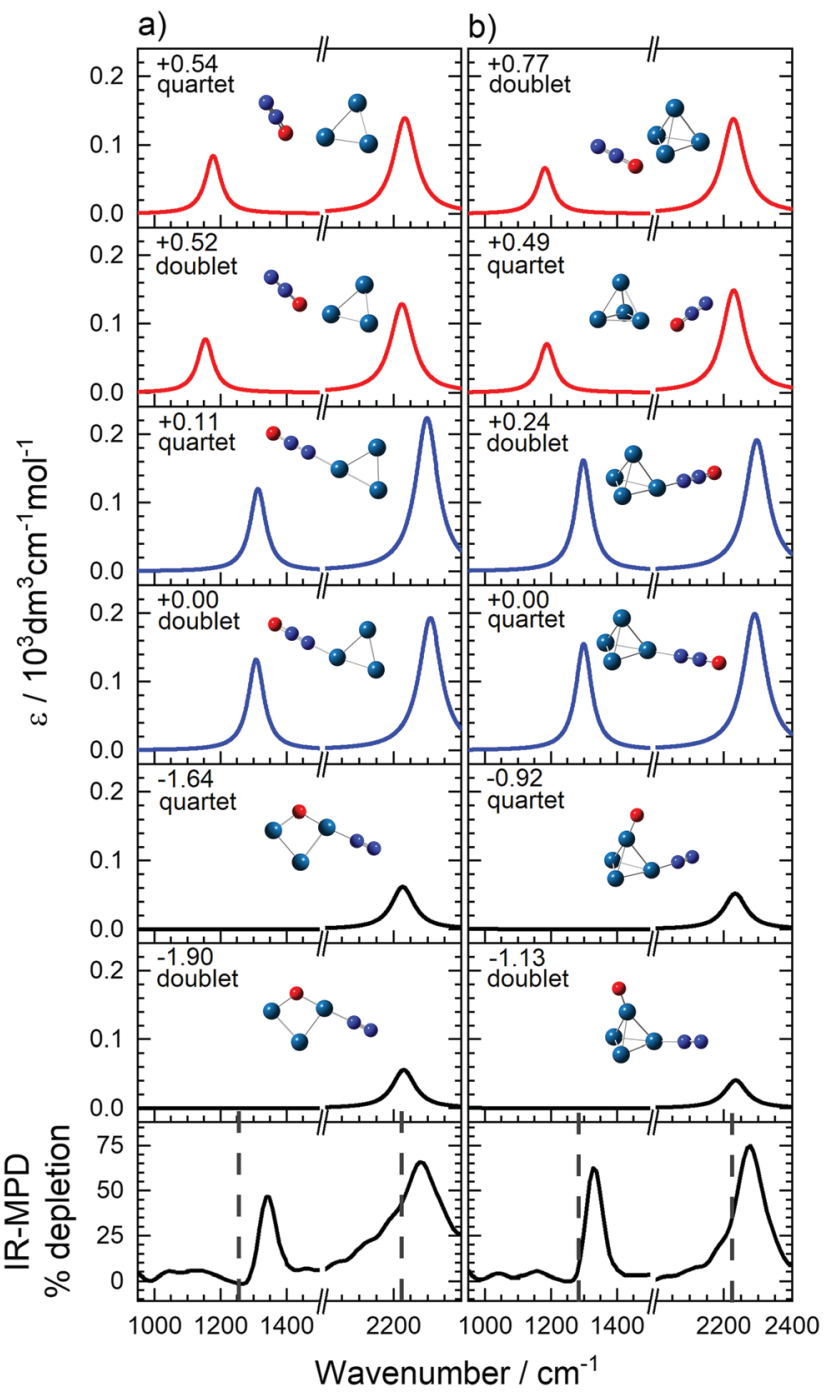

Fig. 5 Comparison of experimental and simulated IR-MPD spectra for a range of low-lying isomers of (a) $\mathrm{Pt}_{3}\left(\mathrm{~N}_{2} \mathrm{O}\right)^{+}$and (b) $\mathrm{Pt}_{4}\left(\mathrm{~N}_{2} \mathrm{O}\right)^{+}$complexes. All molecularly-bound isomers within $1 \mathrm{eV}$ of the lowest energy structure are presented. Blue spectra represent $\mathrm{N}$-bound isomers and red spectra O-bound variants. The dashed lines at $1285 \mathrm{~cm}^{-1}$ and $2224 \mathrm{~cm}^{-1}$ represent the fundamental bands in free $\mathrm{N}_{2} \mathrm{O} .{ }^{50}$

remain bound. The IR-MPD spectra clearly indicate the presence of molecularly-bound structures suggesting a kinetic barrier to dissociation. For this reason we choose the lowest-energy molecularlybound structure as our zero of energy. Low-lying doublet and quartet electronic states are found for both clusters but the $\mathrm{N}$-bound isomers lie lower in energy than corresponding O-bound isomers by approximately $0.5 \mathrm{eV}$ in each case, supporting the assignments of the IR-MPD spectra made above. All structures are bound at single atom rather than bridging sites and the agreement between the simulated spectra and those observed experimentally is so good that there is no need to invoke the presence of any other structures in the beam.

In any infrared action spectrum the depletion of a parent ion signal must be matched by an enhancement in the signal for some daughter species. By tracking parent ion depletions and absolute signal enhancements in different daughter channels 
simultaneously, it is possible to determine the branching ratios for the two most likely possibilities:

$$
\left(\mathrm{N}_{2} \mathrm{O} \text { loss }\right) \quad \mathrm{Pt}_{n}\left(\mathrm{~N}_{2} \mathrm{O}\right)^{+}+h \nu \rightarrow \mathrm{Pt}_{n}^{+}+\mathrm{N}_{2} \mathrm{O},
$$

and

(infrared driven dissociation) $\mathrm{Pt}_{n}\left(\mathrm{~N}_{2} \mathrm{O}\right)^{+}+h \nu \rightarrow \mathrm{Pt}_{n} \mathrm{O}^{+}+\mathrm{N}_{2}$.

Such an analysis is shown in Fig. 6 for $\mathrm{Pt}_{n}\left(\mathrm{~N}_{2} \mathrm{O}\right)^{+}(n=3-5,7,8)$ in the region of the $\mathrm{N}=\mathrm{O}$ stretching mode (with very similar behaviour observed in the $\mathrm{N}=\mathrm{N}$ stretch). A quantitative comparison of product channel enhancements versus parent ion depletion is a real challenge due to multiple species with similar spectra yielding the same fragmentation products. This affects net lineshapes and relative enhancements/depletion signal size in each channel. Nevertheless some clear pictures do emerge. In terms of reactivity, the smaller cluster sizes, $n=3-5$ behave qualitatively differently to the $n=7,8$ clusters. For $\mathrm{Pt}_{n}\left(\mathrm{~N}_{2} \mathrm{O}\right)^{+}$ $(n=3-5)$, excitation of the $\mathrm{N}=\mathrm{O}$ stretch leads almost exclusively to $\mathrm{N}_{2} \mathrm{O}$ loss (process (5)), consistent with the idea that, from the entrance-channel minimum, the $\mathrm{Pt}_{n}{ }^{+}+\mathrm{N}_{2} \mathrm{O}$ dissociation threshold is reached before the transition state leading to nitrous oxide decomposition. By contrast, for $\mathrm{Pt}_{n}\left(\mathrm{~N}_{2} \mathrm{O}\right)^{+}(n=7,8)$, comparable enhancements in both the $\mathrm{Pt}_{n}{ }^{+}$and $\mathrm{Pt}_{n} \mathrm{O}^{+}$daughter channels (processes (5) and (6)) imply that the reactive transition state lies below or at a comparable energy to the dissociation threshold. These observations are in good agreement with the reactivity data extracted from the time-of-flight spectra even down to the small $\mathrm{Pt}_{3} \mathrm{O}^{+}$production following excitation of $\mathrm{Pt}_{3}\left(\mathrm{~N}_{2} \mathrm{O}\right)^{+}$. a)

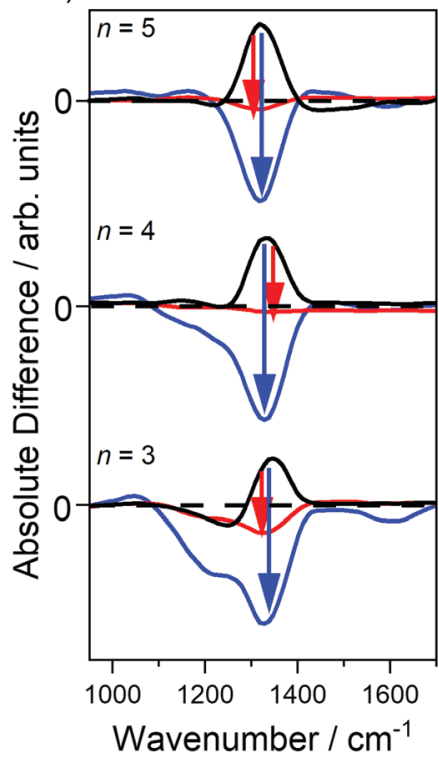

b)

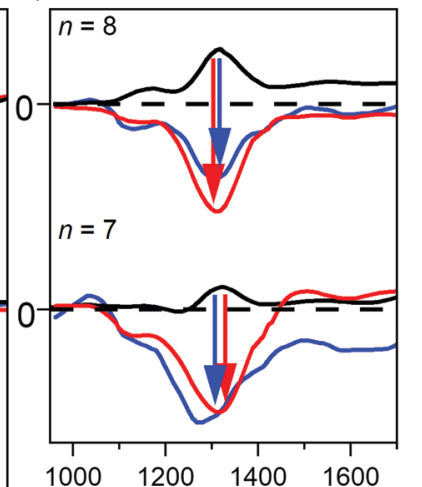

Wavenumber $/ \mathrm{cm}^{-1}$

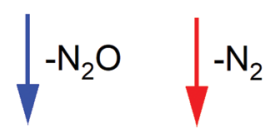

Fig. 6 (black) IR-MPD spectra of $\mathrm{Pt}_{n}\left(\mathrm{~N}_{2} \mathrm{O}\right)^{+}$clusters in the $\mathrm{N}_{2} \mathrm{O}(\mathrm{N}=\mathrm{O})$ stretch region. Red and blue spectra show the simultaneous enhancements observed in the $\mathrm{Pt}_{n} \mathrm{O}^{+}$and $\mathrm{Pt}_{n}{ }^{+}$mass channels representing IR driven reactive ( $\mathrm{N}_{2}$ loss) and desorptive $\left(\mathrm{N}_{2} \mathrm{O}\right.$ loss) processes.
Observation of efficient generation of the $\mathrm{Pt}_{n} \mathrm{O}^{+}$daughter is a signal of infrared-induced chemistry on the surface of the cluster, a process which we have documented in several previous studies of other systems including $\mathrm{Rh}_{n}\left(\mathrm{~N}_{2} \mathrm{O}\right)^{+}, 32,33$ $\mathrm{Rh}_{n} \mathrm{O}\left(\mathrm{N}_{2} \mathrm{O}\right)^{+},{ }^{32,34} \mathrm{Pt}_{n} \mathrm{O}_{2}(\mathrm{CO})^{+},{ }^{45}$ and, recently, $\mathrm{Au}_{n}(\mathrm{OCS})^{+}{ }^{54}$ In several previous studies ${ }^{32,36}$ we have also demonstrated that the products observed following infrared excitation mirror those of collisional activation implying that we essentially "heat" the entrance-channel complexes until dissociation/reactive channels open. Previous studies have not revealed any mode-selective character to the chemistry induced and the current system is no exception. However, the ability to selectively increase the internal energy of a known cluster with spectral knowledge of its structure represents a unique feature in the exploration of these catalytically-relevant reactive potential energy surfaces.

\section{Summary and conclusions}

A combined experimental (IR-MPD) and computational study of nitrous oxide reacting with and binding to platinum cluster cations, $\mathrm{Pt}_{n}{ }^{+}(n=3-8)$, has revealed key features on the potential energy surface of the $\mathrm{Pt}_{n}^{+}+\mathrm{N}_{2} \mathrm{O} \rightarrow \mathrm{Pt}_{n} \mathrm{O}^{+}+\mathrm{N}_{2}$ reaction. The laser ablation/molecular beam conditions employed in this study are shown, in most cases, to lead to the efficient formation of entrance-channel complexes on the reactive surface, the structures of which can be probed by multiple-photon dissociation action spectroscopy. One notable exception is the $\mathrm{Pt}_{6}{ }^{+}$cluster, which reacts completely to generate the oxide with no evidence of $\mathrm{Pt}_{6}\left(\mathrm{~N}_{2} \mathrm{O}\right)^{+}$observed.

The observed reactivity can be well-understood in terms of potential energy surfaces calculated at the DFT level. Similarly, the simulated vibrational spectra for calculated low-energy entrance-channel complexes match well with the action spectra recorded. For several cluster sizes, clear evidence for infrared-driven cluster chemistry is observed in the loss of $\mathrm{N}_{2}$ following infrared excitation of the $\mathrm{N}=\mathrm{O}$ stretching mode of the parent $\mathrm{Pt}_{n}\left(\mathrm{~N}_{2} \mathrm{O}\right)^{+}$. These results, too, are in quantitative agreement with calculated reactive barrier heights compared to $\mathrm{N}_{2} \mathrm{O}$ binding energies.

\section{Conflicts of interest}

There are no conflicts to declare.

\section{Acknowledgements}

This work was funded in part by EPSRC under Programme Grant EP/L005913. The Oxford authors would like to acknowledge the use of the University of Oxford Advanced Research Computing (ARC) facility in carrying out this work: https://doi. org/10.5281/zenodo.22558. Financial support permitting research visits is also gratefully acknowledged from the Oxford-Berlin Research Partnership (Ref.: OXBER_STEM5, “A Collaborative Approach to Understanding Nitrogen Oxide Reduction at Metal Centres”). G. M. and A. E. G. thank Worcester and Magdalen Colleges, Oxford, respectively for their graduate studentships. A. F. thanks the Deutsche Forschungsgemeinschaft for his 
Heisenberg Grant (FI893/5). Open Access funding provided by the Oxford University Agreement.

\section{References}

1 J. Pérez-Ramírez, F. Kapteijn, K. Schöffel and J. A. Moulijn, Appl. Catal., B, 2003, 44, 117-151.

2 WMO (World Meteorological Organization), Scientific Assessment of Ozone Depletion: 2018, Global Ozone Research and Monitoring Project-Report No. 58, 588 pp., Geneva, Switzerland, 2018.

3 A. R. Ravishankara, J. S. Daniel and R. W. Portmann, Science, 2009, 326, 123.

4 UNEP 2015, Synthesis of the 2014 Reports of the Scientific, Environmental Effects, and Technology \& Economic Assessment Panels of the Montreal Protocol, United Nations Environment Programme (UNEP), Nairobi.

5 V. Rosca, M. Duca, M. T. de Groot and M. T. M. Koper, Chem. Rev., 2009, 109, 2209-2244.

6 G. Chinchen, P. Davies and R. J. Sampson, in Catalysis: Science and Technology, ed. J. R. Anderson and M. Boudart, Springer, Berlin, Heidelberg, 1987, vol. 8, pp. 1-67.

7 R. C. Stempel and S. W. Martens, SAE Trans., 1974, 83, 2358-2372.

8 A. Cho, Science, 2003, 299, 1684-1685.

9 A. Ulvestad, A. Singer, J. N. Clark, H. M. Cho, J. W. Kim, R. Harder, J. Maser, Y. S. Meng and O. G. Shpyrko, Science, 2015, 348, 1344-1347.

10 M. B. Knickelbein, Annu. Rev. Phys. Chem., 1999, 50, 79-115.

11 D. K. Böhme and H. Schwarz, Angew. Chem., Int. Ed., 2005, 44, 2336-2354.

12 D. J. Trevor, R. L. Whetten, D. M. Cox and A. Kaldor, J. Am. Chem. Soc., 1985, 107, 518-519.

13 D. J. Trevor, D. M. Cox and A. Kaldor, J. Am. Chem. Soc., 1990, 112, 3742-3749.

14 T. Hanmura, M. Ichihashi and T. Kondow, J. Phys. Chem. A, 2002, 106, 11465-11469.

15 G. S. Jackson, F. M. White, C. L. Hammill, R. J. Clark and A. G. Marshall, J. Am. Chem. Soc., 1997, 119, 7567-7572.

16 C. Adlhart and E. Uggerud, Chem. - Eur. J., 2007, 13, 6883-6890.

17 C. Adlhart and E. Uggerud, Chem. Commun., 2006, 2581-2582.

18 U. Achatz, C. Berg, S. Joos, B. S. Fox, M. K. Beyer, G. NiednerSchatteburg and V. E. Bondybey, Chem. Phys. Lett., 2000, 320, 53-58.

19 M. Andersson and A. Rosén, J. Chem. Phys., 2002, 117, 7051-7054.

20 H. Yamamoto, K. Miyajima, T. Yasuike and F. Mafuné, J. Phys. Chem. A, 2013, 117, 12175-12183.

21 K. Koszinowski, D. Schröder and H. Schwarz, J. Phys. Chem. A, 2003, 107, 4999-5006.

22 I. Balteanu, O. Petru Balaj, M. K. Beyer and V. E. Bondybey, Phys. Chem. Chem. Phys., 2004, 6, 2910-2913.

23 P. A. Hintz and K. M. Ervin, J. Chem. Phys., 1995, 103, 7897-7906. 24 L. Lv, Y. Wang, Q. Wang and H. Liu, J. Phys. Chem. C, 2010, 114, 17610-17620.
25 P. Ferrari, K. Hansen, P. Lievens and E. Janssens, Phys. Chem. Chem. Phys., 2018, 20, 29085-29090.

26 A. E. Green, J. Justen, W. Schöllkopf, A. S. Gentleman, A. Fielicke and S. R. Mackenzie, Angew. Chem., Int. Ed., 2018, 57, 14822-14826.

27 Y. Shi and K. M. Ervin, J. Chem. Phys., 1998, 108, 1757-1760.

28 O. P. Balaj, I. Balteanu, T. T. J. Roßteuscher, M. K. Beyer and V. E. Bondybey, Angew. Chem., Int. Ed., 2004, 43, 6519-6522.

29 E. M. Cunningham, A. S. Gentleman, P. W. Beardsmore, A. Iskra and S. R. Mackenzie, J. Phys. Chem. A, 2017, 121, 7565-7571.

30 E. M. Cunningham, A. S. Gentleman, P. W. Beardsmore and S. R. Mackenzie, Phys. Chem. Chem. Phys., 2019, 21, 13959-13967.

31 E. M. Cunningham, A. S. Gentleman, P. W. Beardsmore and S. R. Mackenzie, Mol. Phys., 2019, 117, 2990-3000.

32 S. M. Hamilton, W. S. Hopkins, D. J. Harding, T. R. Walsh, M. Haertelt, C. Kerpal, P. Gruene, G. Meijer, A. Fielicke and S. R. Mackenzie, J. Phys. Chem. A, 2011, 115, 2489-2497.

33 S. M. Hamilton, W. S. Hopkins, D. J. Harding, T. R. Walsh, P. Gruene, M. Haertelt, A. Fielicke, G. Meijer and S. R. Mackenzie, J. Am. Chem. Soc., 2010, 132, 1448-1449.

34 A. C. Hermes, S. M. Hamilton, W. S. Hopkins, D. J. Harding, C. Kerpal, G. Meijer, A. Fielicke and S. R. Mackenzie, J. Phys. Chem. Lett., 2011, 2, 3053-3057.

35 I. S. Parry, A. Kartouzian, S. M. Hamilton, O. P. Balaj, M. K. Beyer and S. R. Mackenzie, Angew. Chem., Int. Ed., 2015, 54, 1357-1360.

36 I. S. Parry, A. Kartouzian, S. M. Hamilton, O. P. Balaj, M. K. Beyer and S. R. Mackenzie, J. Phys. Chem. A, 2013, 117, 8855-8863.

37 W. Schöllkopf, S. Gewinner, H. Junkes, A. Paarmann, G. von Helden, H. Bluem and A. M. Todd, Proc. SPIE, 2015, 9512, 95121L.

38 A. Yanagimachi, K. Koyasu, D. Y. Valdivielso, S. Gewinner, W. Schöllkopf, A. Fielicke and T. Tsukuda, J. Phys. Chem. C, 2016, 120, 14209-14215.

39 A. Fielicke, G. von Helden and G. Meijer, Eur. Phys. J. D, 2005, 34, 83-88.

40 F. Weigend and R. Ahlrichs, Phys. Chem. Chem. Phys., 2005, 7, 3297-3305.

41 V. N. Staroverov, G. E. Scuseria, J. Tao and J. P. Perdew, J. Chem. Phys., 2003, 119, 12129-12137.

42 J. Tao, J. P. Perdew, V. N. Staroverov and G. E. Scuseria, Phys. Rev. Lett., 2003, 91, 146401.

43 M. J. Frisch, G. W. Trucks, H. B. Schlegel, G. E. Scuseria, M. A. Robb, J. R. Cheeseman, G. Scalmani, V. Barone, G. A. Petersson, H. Nakatsuji, X. Li, M. Caricato, A. V. Marenich, J. Bloino, B. G. Janesko, R. Gomperts, B. Mennucci, H. P. Hratchian, J. V. Ortiz, A. F. Izmaylov, J. L. Sonnenberg, D. Williams-Young, F. Ding, F. Lipparini, F. Egidi, J. Goings, B. Peng, A. Petrone, T. Henderson, D. Ranasinghe, V. G. Zakrzewski, J. Gao, N. Rega, G. Zheng, W. Liang, M. Hada, M. Ehara, K. Toyota, R. Fukuda, J. Hasegawa, M. Ishida, T. Nakajima, Y. Honda, O. Kitao, H. Nakai, T. Vreven, K. Throssell, J. A. Montgomery Jr., J. E. Peralta, F. Ogliaro, M. J. Bearpark, J. J. Heyd, E. N. Brothers, K. N. Kudin, V. N. Staroverov, T. A. Keith, R. Kobayashi, J. Normand, 
K. Raghavachari, A. P. Rendell, J. C. Burant, S. S. Iyengar, J. Tomasi, M. Cossi, J. M. Millam, M. Klene, C. Adamo, R. Cammi, J. W. Ochterski, R. L. Martin, K. Morokuma, O. Farkas, J. B. Foresman and D. J. Fox, Gaussian 16 Revision C.01, Gaussian, Inc., Wallingford CT, 2016.

44 K. P. Jensen, J. Phys. Chem. A, 2009, 113, 10133-10141.

45 A. C. Hermes, S. M. Hamilton, G. A. Cooper, C. Kerpal, D. J. Harding, G. Meijer, A. Fielicke and S. R. Mackenzie, Faraday Discuss., 2012, 157, 213-225.

46 A. Fielicke, P. Gruene, M. Haertelt, D. J. Harding and G. Meijer, J. Phys. Chem. A, 2010, 114, 9755-9761.

47 D. J. Harding, C. Kerpal, D. M. Rayner and A. Fielicke, J. Chem. Phys., 2012, 136, 211103.

48 S. Grimme, S. Ehrlich and L. Goerigk, J. Comput. Chem., 2011, 32, 1456-1465.
49 D. Andrae, U. Häußermann, M. Dolg, H. Stoll and H. Preuß, Theor. Chim. Acta, 1990, 77, 123-141.

50 G. Herzberg, Molecular Spectra and Molecular Structure: II Infrared and Raman Spectra of Polyatomic Molecules, Krieger, Malabar, Florida, 1991.

51 K. Fukui, Acc. Chem. Res., 1981, 14, 363-368.

52 H. P. Hratchian and H. B. Schlegel, Theory and Applications of Computational Chemistry: The First 40 Years, Elsevier, Amsterdam, 2005.

53 C. Kerpal, D. J. Harding, A. C. Hermes, G. Meijer, S. R. Mackenzie and A. Fielicke, J. Phys. Chem. A, 2013, 117, 1233-1239.

54 A. E. Green, S. Schaller, G. Meizyte, B. J. Rhodes, S. P. Kealy, A. S. Gentleman, W. Schöllkopf, A. Fielicke and S. R. Mackenzie, J. Phys. Chem. A, 2020, 124, 5389-5401. 